\title{
Grapevine Red Blotch Disease Affects Carbohydrate Homeostasis and Cell Call Characteristics in Vitis Vinifera L.
}

\author{
Prashant Swamy ( $\sim$ prashant.swamy@wsu.edu ) \\ Washington State University \\ Sivakumar Pattathil \\ Mascoma LLC (Lallemand Inc.) \\ Faride Unda \\ University of British Columbia \\ Shawn D. Mansfield \\ University of British Columbia
}

\section{Research Article}

Keywords: Grapevine viruses, Grapevine red blotch disease, cell wall, carbohydrates, pectin, xyloglucans

Posted Date: April 21st, 2021

DOI: https://doi.org/10.21203/rs.3.rs-428067/v1

License: (c) (i) This work is licensed under a Creative Commons Attribution 4.0 International License. Read Full License 


\section{Abstract}

\section{Background}

Grapevines are commonly infected with one or more viruses causing a significant threat to the sustainability of quality wine grape production worldwide. The recently identified Grapevine red blotch disease (GRBD) significantly affects the yield and quality of wine grapes. It is largely unknown how the red blotch disease affects carbohydrate homeostasis and regulate the source-to-sink relationship in grapevines. We took an integrative approach to determine the consequences of viral infection in commercially grown, two popular wine grape cultivars from distinct locations in the eastern Washington.

\section{Results}

The deep sequencing approach revealed that Grapevine red blotch virus (GRBV) was found in all symptomatic vines, while asymptomatic vines were free of this virus. Analysis of mature berries at commercial harvest in virus-infected vines indicated significant changes in the soluble sugar accumulation along with the increase in leaf sucrose and starch content. To follow up with the altered carbohydrate homeostasis, we analyzed cell wall components in winter canes of virus-infected vines and compared them to their virus-free counterparts. Major cell wall monosaccharide contents and total lignin content was not affected due to red blotch disease in either cultivar. However, high-resolution glycome profiling revealed consistent changes in loosely bound cell wall pectin matrices and tightly bound non-fucosylated xyloglucans in virus-infected vines. Furthermore, in cv. Syrah, co-infection with other viruses leads to additional cell wall compositional variations.

\section{Conclusions}

These changes highlighted that virus infection in woody perennial leads to detrimental adjustments in the soluble and storage carbohydrates, and in the cell wall layers that could be attributed to lower vine performance or vine decline in a relatively short time. The information gained from such qualitative cell wall structural fine-tuning could be used in assessing how viruses or other pathogenic agents affect perennial longevity.

\section{Background}

Wine grapes are currently the highest value fruit crop in the United States comprising a nearly $\$ 5$ billion industry. The sustainability of grape production is often threatened by various biotic and abiotic stresses. Frequently, grapes are infected with multiple viruses due to the perennial nature, but also as a consequence of vegetative propagation. Vine performance of virus-infected grapevines declines over time, often manifesting in reduced fruit yield, berry quality, and in some cases, vine death. This is because once infected, the virus continues to affect the vine's physiological performance throughout its life. Grapevine red blotch disease (GRBD) presumably caused by Grapevine red blotch virus (GRBV) were recently discovered in California [1] and Washington vineyards [2], and shown to affect several wine grape cultivars [3]. GRBD causes a significant reduction in berry sugar accumulation while accumulating sucrose and starch in the leaves possibly giving rise to reddish-purple foliar coloration due to increased anthocyanin production [2], which is often triggered by sucrose concentrations $[4,5]$. Consistent with this idea, sucrose metabolism in the grapevines infected with GRBD can be greatly affected by changing the source-to-sink relationship. The systemic changes that occur due to GRBD may therefore be subject to alteration in several biosynthetic pathways, as is the case in vines infected with grapevine leafroll disease (GLD) [6].

GRBV is a single-stranded 3.2 kb DNA virus, a member of the Geminiviridae family that can be transmitted by leafhoppers [2]. However, the natural epidemiology of the virus is still unclear [7]. Infected vines exhibit characteristic reddish-purple foliar symptoms especially at post- véraison stage in the red-fruited cultivars, and the leaf symptoms look similar to those infected with grapevine leaf-roll disease (GLD), though not identical. Grapevines are often infected with multiple viruses [8], some of which remain latent and undetected since the infections do not exhibit visual symptoms that prompt their thorough investigation. However, recent advances in sequencing technologies offer unprecedented accuracy and speed for detecting novel, uncharacterized viruses and other infecting agents that were previously misinterpreted as infection by known viruses. Therefore, we embarked on a deep sequencing approach to identify all infecting viruses and viroids in selected grapevine samples from two cultivars, Merlot and Syrah grown commercially in the eastern Washington.

Survival of grapevines through several years of exposure to various viruses depends on the compatible adjustments in vine growth and development. Understanding the structural development of vines through analysis of cell wall composition can provide clues on how viruses can impact cell wall integrity, however, very few studies have been conducted to investigate the impact of viral infection on cell wall architecture. It has been shown that cell wall biosynthetic genes were suppressed in rice infected with Rice Tungro Spherical Virus (RTSV) [9], and global transcript analysis of plants infected with South African Cassava Mosaic Virus (SACMV) showed increased expression of cell wall-related genes [10], but opposite trends were seen in rice infected with Rice Dwarf Virus which resulted in stunted plant growth [11].

Viruses are also known to specifically modulate host pectin methyl esterases (PMEs) to overcome plasmodesmata size, which impacts the exclusion limit for protein movement $[12,13]$. Along with cell wall transcriptome studies, proteomic analyses suggested that viral infection can alter cell wallrelated proteins [14]. However, it is not known whether viral infection influences the biosynthesis or packaging/trafficking of different cell wall components in the plant. Analysis of different cell wall layers has been documented in many species using a range of technologies mainly to investigate biomass properties [15-18]. Based on the fact that GRBV-infected vines had increased leaf sucrose and starch levels [2], we hypothesize that altered 
carbohydrate flux could be re-routed into the structural cell wall assembly. The resulting structural differences, if any, may cause irreversible damage to the grapevines resulting in poor vine performance, compromised fruit yield, and overall berry quality.

\section{Results}

\section{Virus composition}

Next-generation sequencing was employed to characterize viruses and virus-like particles present in the canes of two wine grape cultivars, Merlot and Syrah. Three symptomatic vines from each cultivar from commercial vineyards that showed characteristic reddish-purple foliar coloration at the postveraison stages, indicative of viral infections, were employed in the study while asymptomatic vines were chosen that are adjacent to the symptomatic vines to minimize spatial variation. The sequencing reads post adapter trimming and quality control were mapped to GenBank (viral 1.1 genomic) in CLC Genomics Workbench 8 platform. With an average of $45.75 \mathrm{M}$ paired reads, of which $3.83 \%$ were mapped to viruses and virus-like sequence database (Table 1). All the symptomatic vines from both Merlot and Syrah cultivars contained Grapevine red blotch virus (GRBV), while none of the sequence reads corresponding to asymptomatic vines were mapped to Grapevine red blotch viral genomic sequences (Table 1). The additional viruses found in all samples of both cultivars were Grapevine Fanleaf Virus and Rupestris Stem Pitting Virus. The deep sequencing data was confirmed by the RT-PCR analysis (Figure S1). Three symptomatic and two asymptomatic samples from Syrah cultivar contained Grapevine Syrah Virus, while only two asymptomatic Merlot vines had this virus. Similarly, two viroids, Hop StuntViroid and Grapevine Yellow Speckle Viroid were present in all samples, with greater sequencing depth and complete genome coverage.

\section{Carbohydrate analysis}

At the commercial wine grape harvest, the berries from symptomatic and asymptomatic vines of Merlot and Syrah were analyzed for berry sugar content and the values are expressed as ${ }^{0}$ Brix. The results indicate that the ${ }^{0}$ Brix of berries from symptomatic vines were significantly reduced in both cultivars (Figure 1a). Soluble sugars (glucose, fructose, and sucrose) and starch analysis in mature leaves showed that sucrose and starch concentrations were significantly elevated in symptomatic vines of cv. Merlot whereas starch was accumulated significantly in cv. Syrah, relative to the asymptomatic counterparts (Figure 1b, c). This observation implies an alteration of the source-sink relationship due to virus infection. To understand how these changes reflects structural carbohydrates, we analyzed the structural cell wall carbohydrates and lignin contents. The HPLC analysis of acid-soluble cell wall fraction identified arabinose, galactose, glucose, mannose, rhamnose, and xylose (Table 2), and a comparison of these sugars between symptomatic and asymptomatic vines did not show significant differences. A slight increase in arabinose was apparent in the symptomatic vines of Syrah relative to their asymptomatic counterparts (Table 2). The total Klason lignin contents (acid-soluble and acid-insoluble) were estimated to be approximately 33 and 30 percent in Merlot and Syrah canes, respectively. No significant differences were found in lignin levels between symptomatic and asymptomatic vines of both cultivars. Collectively, the results from structural carbohydrate analysis suggest that GRBV infection did not alter the cell wall composition of GRBV infected grapevine canes, whereas the soluble sugars and starch contents were elevated in source leaves with concurrent reduction of berry sugars.

\section{Glycome analysis}

Glycome profiling analyses were conducted on cell walls fractions isolated from the cane woods of asymptomatic and symptomatic Merlot and Syrah cultivars (Figure 2). Overall, the cell wall glycome profiles were largely similar irrespective of the cultivars or status of viral infection. Glycome profiling studies revealed the overall composition and extractability of diverse matrix cell wall glycans present in all samples studied. In general, xyloglucan epitopes were extracted in all alkaline extracts such as carbonate, $1 \mathrm{M} \mathrm{KOH}, 4 \mathrm{M} \mathrm{KOH}$, and $4 \mathrm{M} \mathrm{KOHPC}$ extracts. Further xylan epitopes (both substituted and unsubstituted xylans) were extracted out in all samples except the oxalate extracts. Pectic backbone epitopes (recognized mainly by HG-backbone-1 and RG-I backbone groups of mAbs) were significantly present in all cell wall samples and followed a mostly identical pattern of extractability. Pectic arabinogalactan epitopes (recognized by RG-I/AG, and AG-1 through 4 groups of mAbs) were also significantly present in all samples, however; their patterns of extractability varied among two varieties. For instance, a marginal increase in the extractability of pectic arabinogalactan epitopes was observed in oxalate and carbonate extracts of Syrah samples compared to Merlot. Subtle variations in the extractability of pectic arabinogalactan epitopes were also noted across asymptomatic and symptomatic samples within a given cultivar. For instance, a reduced abundance of pectic arabinogalactan epitopes was observed in the oxalate and carbonate extracts from symptomatic samples from both cultivars hinting that the viral infection caused cell wall alterations. To further study underlying variations we conducted more in-depth statistical analyses using the raw data as described in the next section.

The glycan extractability of asymptomatic Merlot and Syrah clearly showed varietal differences in cell wall matrix complexity. The antibody binding data was filtered (low-pass binding values were removed) and the remaining immune data was clustered into data self-organizing maps (SOM-clustering). Pectic polysaccharide glycans (epitopes of homogalacturonan backbone and rhamnogalacturonan-1/ arabinogalactans) were extracted at higher levels in the initial mild extracts (Figure 3, cluster 1 and 4) of Syrah compared to Merlot. The second variation was observed in non-fucosylated xyloglucan epitope extractability, with relatively higher levels being recovered during oxalate, carbonate, and $1 \mathrm{M}$ alkali extracts of Merlot than in Syrah. The remaining antibody signal intensities did not vary between two cultivars suggesting any further changes in their cell wall composition were unlikely.

When we compared the differences in the cell wall extractability of virus-free and virus-infected vines, two changes were consistent in both cultivars. First, loosely bound pectic arabinogalactan epitope abundances were reduced in the GRBV infected grapevines. These changes were especially observed 
when the cell wall fractions were extracted with sodium carbonate (SC). The reduction in the extractability was more pronounced in the Syrah cultivar (Figure 3, cluster 4). In the subsequent extracts, we did not observe any detectable changes between GRBV-free and GRBV infected cane samples. Second, GRBV-infection resulted in a specific increase in extractability of non-fucosylated xyloglucan epitopes in stronger alkaline extracts (4M KOH and $4 \mathrm{M} \mathrm{KOHPC)}$, and this was relatively more prominent in Syrah compared to Merlot. This increase was observed in the $4 \mathrm{M} \mathrm{KOH}$ extracts in both cultivars; however, during the strongest alkali extraction (with 4M KOHPC) the Syrah samples showed higher extractability compared to Merlot. In addition to these changes, GRBV infected Syrah exhibited lower xylan epitope extractability in relatively stronger alkali extracts ( $1 \mathrm{M}$ and $4 \mathrm{M}$ KOH). The remaining samples did not show any changes in their extractability. The least affected group of glycan epitopes contained those of galactomannans, epitopes recognized by rhamnogalacturonan-1b group of mAbs, and epitopes recognized by the reminder of the arabinogalactan groups of mAbs (Figure 3 , cluster 3 ). The glycome analysis thus provided insights into how different cell wall carbohydrates are compositionally and structurally packaged in cane woods of wine grapes, and how virus infection changes some of the cell wall architecture compared to their virus-free counterparts.

\section{Discussion}

About 70 different virus and virus-like agents infect grapes worldwide and often spread into other grape-growing regions due to vegetative propagation [8]. Many of the viruses remain undetected since they are asymptomatic, but otherwise affect vine health, crop yield, and fruit quality. In eastern Washington and other grape-growing regions in the United States and Canada, GRBD symptoms are often confused with those displayed due to GLD infections due to the high degree of similarity in their symptom characteristics. Recently, next-generation sequencing has emerged as a very useful technique to accurately diagnose disease, as it is highly sensitive. Next-generation sequencing not only identifies known viruses but also provides an opportunity to find new viruses or viroids in a given sample [19-21]. In plants, it is considered a universal diagnostic tool to identify novel viruses [22, 23]. In wine grapes, GRBV was identified using next-generation sequencing technology in the vines that exhibited Grapevine leafroll-disease like symptoms [2]. Although we did not find novel viral sequences in our wine grapes, many virus co-infections were identified in the vines that were otherwise thought to contain only GRBV. The post-véraison foliar discoloration of GRBD affected Merlot and Syrah vines were correlated with the presence of GRBV in all symptomatic vines and absent in asymptomatic vines with normal senescing leaves. Therefore, we conclude that the disease symptoms were mainly ascribed to GRBV infection.

GRBD in Merlot and Syrah cultivars showed foliar interveinal reddening symptoms at post-véraison similar to those exhibited by GLD. The symptoms were potentially resulted from the re-routing of the flavonoid biosynthetic pathway leading to anthocyanin accumulation in virus-infected leaves [6]. The increase in leaf sucrose was shown as a major contributor to anthocyanin production in leaves [4, 24]. In our experiment, leaf sucrose and starch content were significantly higher in post-véraison leaves of GRBV infected Merlot and Syrah cultivars (Figure 1), while the berries from these same vines were lower in ${ }^{0}$ Brix relative to their asymptomatic vines. Therefore, we suggest that the photoassimilates (sugars) cannot be transported effectively out of the leaf mesophyll cells, largely impacting the sink-source relationship of the infected plants. Consequently, the buildup of sucrose in the leaves triggered anthocyanin production.

Soluble carbohydrates (glucose and sucrose) and starch were elevated in source leaves at berry maturity, perhaps due to a possible hindrance in exporting the sugars out of the source leaf mesophyll cells that resulted in a net increase of photoassimilates at source leaves. This is concurrent with the reduction in berry sugar content (measured as ${ }^{0} \mathrm{Brix}$ ) of GRBD affected vines (Figure 1). The possibility that the elevated carbon pool may be channeled into the cell wall reserve cannot be denied. Therefore, we analyzed the cane wood meal to investigate whether the disease affected cell wall content or its architecture. Structural carbohydrate analysis indicated that viral infection did not cause any significant alteration in the major cell wall carbohydrates and apart from cultivar variations and lignin remain unaltered in both cultivars. Cell wall complex carbohydrates and their synergistic interactions into delicate cell wall architecture had been determined in many species using a suite of monoclonal antibodies directed against specific glycan moieties [15-18]. This analysis indeed helped us understand the compositional changes in cell wall layers that manifest from GRBV infection. The sequential extractability of cell wall glycans in a range of alkali reagents (from mild to strong reagents) highlighted differences in asymptomatic cultivars, as well as GRBV-infected Merlot and Syrah vines. This included subtle changes in extractability of pectic polysaccharides and more pronounced xyloglucan (non-fucosylated) extractability with milder reagents that indicate variations in loosely bound cell wall pectin architecture of both cultivars. Infected samples of both cultivars had unanimity in the lower extractability of pectic polysaccharides and higher non-fucosylated xyloglucans recoveries associated with tightly packaged hemicellulose associated glycans in GRBD infected samples. These two changes signify that GRBD infection may have triggered changes that manifest in the extractability differences in bound pectin and potential loosening of tightly bound hemicellulose complexes (as indicated by their increased extractability in strong alkaline extracts). The magnitude of these changes was severe in Syrah vines (Figure 3, Cluster 6) perhaps owing to cultivar-specific responses to virus infection. Furthermore, lower xylan epitope extractability observed in infected vines hints at altered packaging of hemicellulose matrices. Since deep sequencing results confirmed co-infection with Grapevine Syrah Virus and its synergistic interaction with GRBV may further contribute to pronounced changes in cell wall architecture. Finally, it is not clear whether the higher levels of arabinose in GRBV infected Syrah vines also contribute to the above alterations. These lines of evidence suggest that the modulation of cell wall packaging is affected by phloem-limited virus intrusion in wine grapes. The findings in the present study can be used to validate the connections of loosely bound pectin polysaccharides, arabinose content in the wall, and xyloglucans with the presence of GRBV. Moreover, how virus infection(s) modulates host plants' soluble and structural carbohydrates will be a key to understanding the complexities of virus-host interactions in perennial plants that can have combined effects on cell wall architecture and detrimental effects on the grapevines.

\section{Conclusions}


The virus compositions of the symptomatic and asymptomatic vines were determined using the Next-Gen sequencing platform and found that foliar symptoms correlated with the presence of GRBV. GRBD in red-fruited Merlot and Syrah cultivars altered soluble carbohydrate levels in the berries and photosynthetic leaves. Structural analysis revealed that cell wall architecture was affected mainly in pectin and xyloglucan components of the cell wall which may have detrimental effects on the vine health and vineyard sustainability.

\section{Methods}

\section{Plant materials}

The plant materials, cvs. Merlot and Syrah used in the present study were obtained from commercial vineyards within Horse Heaven Hills AVA and Columbia Valley AVA of eastern Washington. The necessary permissions were obtained from vineyard owners for conducting virus survey, leaf and berry sampling, and follow up studies. The location and names of the vineyard blocks are kept confidential to protect the growers' identity.

\section{Vine sampling}

Berries from five symptomatic and five asymptomatic vines of cv. Merlot and Syrah were sampled at commercial harvest. Berry analysis procedures were followed as per [25] with slight modifications. Briefly, 30 random berries from different clusters were collected from both sides of the vine and each cordon. The pedicels were kept intact at $4{ }^{0} \mathrm{C}$ until analyses. The berries from symptomatic vines were then pooled, mixed well, and distributed into five separate samples to facilitate more random representation and minimize vine to vine variation. Berries from asymptomatic vines were treated similarly. Later, pedicels were removed and berry maturity indices were measured. Mature leaves were collected from the corresponding vines which showed no visible damage to the blade (except reddish-purple coloration of symptomatic leaves) and immediately frozen in liquid nitrogen until storage in $-80{ }^{0} \mathrm{C}$.

\section{$\underline{\text { RNA isolation }}$}

Canes from actively growing symptomatic and asymptomatic vines at post- véraison stage were used to obtain cambial scrapping (after de-barking) into liquid nitrogen and stored at $-80{ }^{\circ} \mathrm{C}$ until use. The phloem (cane) RNA was prepared using Spectrum Plant Total RNA kit (Cat \# STRN 50-1KT, SigmaAldrich Inc.), where total RNA was treated with RNase-free DNase (Cat\# 79254, Qiagen Inc.) following manufacturer's instructions. The integrity and concentration were assessed using Agilent 2100 Bioanalyzer instrument (Agilent Inc.). Only RNA samples with RIN >7.5 were subsequently used in NextGen sequencing experiments.

\section{Deep sequencing}

High-quality phloem RNA was subjected to library preparation using Illumina TruSeq Stranded Total RNA kit with Ribo-zero Plant at Huntsman Cancer Institute, University of Utah. Sequencing was performed on an Illumina HiSeq2500 for 125 cycles from both ends. Post-trimmed data were imported into CLC Genomics Workbench (Qiagen Inc.) and sequence reads were mapped to the viral genome database from Genebank (viral 1.1 genomic) that was used as a reference for mapping quarry read sequences. The presence of viral genome in the sample was confirmed by a high mapping percentage (>85\%) and greater sequencing depth as indicated by an average number of the read mappings.

\section{Carbohydrate analysis}

Berry sugar content was determined using PAL-1 pocket refractometer (Spectrum Technologies, Inc.) and expressed as ${ }^{0}$ Brix or total soluble sugars (TSS). Leaf soluble carbohydrates were determined as described earlier [26]. Briefly, lyophilized leaf tissue powder w0061s were subjected to sequential analysis of glucose, fructose, and sucrose via enzymatic assays. The water-insoluble fraction from soluble carbohydrate analysis was employed to determine starch content using Starch Assay kit (STA20, Sigma-Aldrich Corp.) and determined spectrophotometrically on an EON spectrometer (BioTek Inc.).

To analyze structural carbohydrates, winter cane tissues were air-dried for several days and ground to pass a \#40 mesh on a Wiley Mill. Alcohol insoluble residues (AIR) were prepared by soxhlet extraction of tissues in hot ethanol and AIR residues were used in scale-down Klason lignin determination protocol modified from laboratory analytical procedure, National Renewable Energy Laboratory (NREL), U.S. Department of Energy as per [18]. Total lignin was expressed as a mixture of acid-soluble and acid-insoluble lignin. The aliquots from acid hydrolysates were used in major cell wall sugars determination using anion exchange HPLC with appropriate sugar standards (arabinose, rhamnose, galactose, glucose, mannose, and fucose) as per [27]. The resulting peak areas corresponding to each major sugar were used in extrapolating cell wall carbohydrate percentages.

\section{Glycome profiling}

Alcohol insoluble residues from asymptomatic and GRBD affected wine grape cvs. Merlot and Syrah cane samples were subjected to glycome profiling using a comprehensive suite of 155 monoclonal antibodies (mAbs) directed against most major non-cellulosic glycan epitopes [28]. Glycome profiling involves sequential extraction of cell wall materials with increasingly harsh reagents thereby generating extracts enriched with glycan components based on relative tightness with which they are bound to the cell wall. For instance, pectic polysaccharides, loosely bound xyloglucans (fucosylated and non-fucosylated), and loosely bound xylans are usually extracted in the initial milder extraction conditions (oxalate and carbonate). The majority of tightly bound xyloglucans, xylans, and pectic polysaccharides are isolated under stronger alkaline extraction conditions ( $1 \mathrm{M}$ and $4 \mathrm{M} \mathrm{KOH})$. More tightly bound lignin associated wall glycans are released at acidic chlorite extraction. Finally, the remaining most tightly bound matrix constituents are 
extracted with post chlorite 4M KOH extraction (4M KOHPC). These extracts were subsequently screened with the comprehensive suite of $155 \mathrm{mAbs}$ [28, 29] to monitor abundances of epitopes present in most major plant cell wall non-cellulosic glycans. Various cell wall glycan-directed mAbs used in glycome profiling were procured from laboratory stocks (CCRC, JIM, and MAC series) at the Complex Carbohydrate Research Center (available through CarboSource Services; http://www.carbosource.net or were obtained from BioSupplies (Australia) (BG1, LAMP).

\section{Data analysis}

The deep sequencing data were analyzed using the CLC Genomics Workbench (Qiagen Inc.) using standard tools. Reference viral sequences from Genebank were imported (viral. 1.1genomic-1) into the CLC genomics workbench and mapped using default parameters. Sequencing depth and mapping percentage were used to determine the presence/ absence of the virus. Analyses of compositional differences were achieved by SOM (selforganizing maps) clustering of antibody binding intensities using MeV v4.9 [30]. The data was then visualized using "R" (https://cran.r-project.org/).

\section{Abbreviations}

GRBD: Grapevine red blotch disease

GRBV: Grapevine red blotch virus

GLD: Grapevine leaf-roll disease

$\mathrm{kb}$ : kilobases

RTSV: Rice Tungro Spherical Virus

SACMV: South African Cassava Mosaic Virus

PMEs: pectin methyl esterases

M: million

cv, cvs: cultivar (s)

suc: sucrose

glc: glucose

fru: fructose

$\mathrm{KOH}$ : Potassium hydroxide

KOHPC: Potassium hydroxide perchlorate

HG: homogalacturonan

RG: rhamnogalacturonan

AG: arabinogalactan

SOM: self-organizing maps

SC: sodium carbonate

RIN: RNA integrity number

TSS: total soluble solids

AIR: alcohol insoluble residue

NREL: National Renewable Energy Laboratory

mABs: monoclonal antibodies

SD: standard deviation

\section{Declarations}

\section{Ethics approval and consent to participate}


Not applicable.

\section{Consent for publication}

Not applicable.

\section{Availability of data and material}

The datasets generated and/ or analyzed during the current study are not publicly available due to protecting commercial interests of the Washington grape growers but are available from the corresponding author on reasonable request.

\section{Competing interests}

The authors declare that they have no competing interests.

\section{Funding}

Funding for this project, including assistantship to PS, was provided by the Washington Wine Commission. The funding body had no role in the design of the study, collection, analysis, and interpretation of data and in writing or revising this manuscript.

\section{Authors' contributions}

PS conceived and designed the study; PS, SP, FU performed the experiments, PS analyzed the data and wrote the manuscript. PS, SP, and SDM critically revised the manuscript. All authors read and approved the final manuscript.

\section{Acknowledgments}

Author thanks two anonymous Washington wine grape growers for their generosity in allowing access to their vineyards and field samplings We thank Dr. Liangjiao Xue for his assistance in data analysis.

\section{References}

1. Al Rwahnih M, Dave A, Anderson MM, Rowhani A, Uyemoto JK, Sudarshana MR: Association of a DNA Virus with Grapevines Affected by Red Blotch Disease in California. Phytopathology 2013, 103(10):1069-1076.

2. Poojari S, Alabi OJ, Fofanov VY, Naidu RA: A Leafhopper-Transmissible DNA Virus with Novel Evolutionary Lineage in the Family Geminiviridae Implicated in Grapevine Redleaf Disease by Next-Generation Sequencing. Plos One 2013, 8(6).

3. Sudarshana MR, Perry KL, Fuchs MF: Grapevine Red Blotch-Associated Virus, an Emerging Threat to the Grapevine Industry. Phytopathology 2015, 105(7):1026-1032.

4. Solfanelli C, Poggi A, Loreti E, Alpi A, Perata P: Sucrose-specific induction of the anthocyanin biosynthetic pathway in Arabidopsis. Plant Physiology 2006, 140(2):637-646.

5. Cormier F, Crevier HA, Do CB: Effects of sucrose concentration on the accumulation of anthocyanins in grape (Vitis vinifera) cell suspension. Canadian Journal of Botany-Revue Canadienne De Botanique 1990, 68(8):1822-1825.

6. Gutha LR, Casassa LF, Harbertson JF, Naidu RA: Modulation of flavonoid biosynthetic pathway genes and anthocyanins due to virus infection in grapevine (Vitis vinifera L.) leaves. Bmc Plant Biology 2010, 10.

7. Perry KL, McLane H, Hyder MZ, Dangl GS, Thompson JR, Fuchs MF: Grapevine red blotch-associated virus is Present in Free-Living Vitis spp. Proximal to Cultivated Grapevines. Phytopathology 2016, 106(6):663-670.

8. Martelli GP: Directory of virus and virus-like diseases of the grapevines and their agents. J Plant Patho/ 2014, 96(1):1-136.

9. Budot BO, Encabo JR, Ambita IDV, Atienza-Grande GA, Satoh K, Kondoh H, Ulat VJ, Mauleon R, Kikuchi S, Choi IR: Suppression of cell wall-related genes associated with stunting of Oryza glaberrima infected with Rice tungro spherical virus. Frontiers in Microbiology 2014, 5:9.

10. Allie F, Pierce EJ, Okoniewski MJ, Rey C: Transcriptional analysis of South African cassava mosaic virus-infected susceptible and tolerant landraces of cassava highlights differences in resistance, basal defense and cell wall associated genes during infection. Bmc Genomics 2014, 15.

11. Shimizu T, Satoh K, Kikuchi S, Omura T: The repression of cell wall- and plastid-related genes and the induction of defense-related genes in rice plants infected with Rice dwarf virus. Molecular Plant-Microbe Interactions 2007, 20(3):247-254.

12. Lionetti V, Cervone F, Bellincampi D: Methyl esterification of pectin plays a role during plant-pathogen interactions and affects plant resistance to diseases. Journal of Plant Physiology 2012, 169(16):1623-1630.

13. Lazarowitz SG: Probing plant cell structure and function with viral movement proteins. Curr Opin Plant Bio/ 1999, 2(4):332-338.

14. Di Carli M, Benvenuto E, Donini M: Recent Insights into Plant-Virus Interactions through Proteomic Analysis. J Proteome Res 2012, 11(10):47654780.

15. De Souza AP, Kamei CLA, Torres AF, Pattathil S, Hahn MG, Trindade LM, Buckeridge MS: How cell wall complexity influences saccharification efficiency in Miscanthus sinensis. Journal of Experimental Botany 2015, 66(14):4351-4365. 
16. Pattathil S, Avci U, Baldwin D, Swennes AG, McGill JA, Popper Z, Bootten T, Albert A, Davis RH, Chennareddy C et al: A Comprehensive Toolkit of Plant Cell Wall Glycan-Directed Monoclonal Antibodies. Plant Physiology 2010, 153(2):514-525.

17. Pattathil S, Ingwers MW, Victoriano OL, Kandemkavil S, McGuire MA, Teskey RO, Aubrey DP: Cell Wall Ultrastructure of Stem Wood, Roots, and Needles of a Conifer Varies in Response to Moisture Availability. Frontiers in Plant Science 2016, 7.

18. Swamy PS, Hu H, Pattathil S, Maloney VJ, Xiao H, Xue LJ, Chung JD, Johnson VE, Zhu YY, Peter GF et al: Tubulin perturbation leads to unexpected cell wall modifications and affects stomatal behaviour in Populus. Journal of Experimental Botany 2015, 66(20):6507-6518.

19. Bexfield N, Kellam P: Metagenomics and the molecular identification of novel viruses. Veterinary Journal 2011, 190(2):191-198.

20. Peng XX, Chan EY, Li Y, Diamond DL, Korth MJ, Katze MG: Virus-host interactions: from systems biology to translational research. Current Opinion in Microbiology 2009, 12(4):432-438.

21. Barba M, Czosnek H, Hadidi A: Historical Perspective, Development and Applications of Next-Generation Sequencing in Plant Virology. Viruses-Basel 2014, 6(1):106-136.

22. Adams IP, Glover RH, Monger WA, Mumford R, Jackeviciene E, Navalinskiene M, Samuitiene M, Boonham N: Next-generation sequencing and metagenomic analysis: a universal diagnostic tool in plant virology. Molecular Plant Pathology 2009, 10(4):537-545.

23. Reingold V, Lachman O, Sela N, Luria N, Dombrovsky A: Watermelon Fruit Rot Disease in Israel is Caused by a Distinct Squash vein yellowing virus (SqVYV) Strain. Plant Disease 2016, 100(6):1176-1183.

24. Payyavula RS, Singh RK, Navarre DA: Transcription factors, sucrose, and sucrose metabolic genes interact to regulate potato phenylpropanoid metabolism. Journal of Experimental Botany 2013, 64(16):5115-5131.

25. Alabi OJ, Casassa F, Gutha LR, Larsen RC, Henick-Kling T, Harbertson JF, Naidu RA: Impacts of Grapevine Leafroll Disease on Fruit Yield and Grape and Wine Chemistry in a Wine Grape (Vitis vinifera L.) Cultivar. Plos One 2016, 11(2):18.

26. Zhao D, MacKown CT, Starks PJ, Kindiger BK: Rapid Analysis of Nonstructural Carbohydrate Components in Grass Forage Using Microplate Enzymatic Assays. Crop Science 2010, 50(4):1537-1545.

27. Porth I, Klapste J, Skyba O, Lai BSK, Geraldes A, Muchero W, Tuskan GA, Douglas CJ, El-Kassaby YA, Mansfield SD: Populus trichocarpa cell wall chemistry and ultrastructure trait variation, genetic control and genetic correlations. New Phytol 2013, 197(3):777-790.

28. Pattathil S, Avci U, Miller JS, Hahn MG: Immunological Approaches to Plant Cell Wall and Biomass Characterization: Glycome Profiling. In: Biomass Conversion: Methods and Protocols. Edited by Himmel ME. Totowa, NJ: Humana Press; 2012: 61-72.

29. Pattathil S, Hahn MG, Dale BE, Chundawat SPS: Insights into plant cell wall structure, architecture, and integrity using glycome profiling of native and AFEX (TM)-pre-treated biomass. Journal of Experimental Botany 2015, 66(14):4279-4294.

30. Saeed Al, Sharov V, White J, Li J, Liang W, Bhagabati N, Braisted J, Klapa M, Currier T, Thiagarajan M et al: TM4: A free, open-source system for microarray data management and analysis. Biotechniques 2003, 34(2):374-+.

\section{Tables}

Table 1. Identification of virus and virus-like sequences in the winter cane of cvs. Merlot and Syrah.

\begin{tabular}{|c|c|c|c|c|c|c|c|c|c|c|c|c|c|}
\hline & & \multicolumn{6}{|c|}{ cv. Merlot } & \multicolumn{6}{|c|}{ cv. Syrah } \\
\hline & & $\mathrm{H} 1$ & $\mathrm{H} 2$ & $\mathrm{H} 3$ & 11 & 12 & 13 & $\mathrm{H} 1$ & $\mathrm{H} 2$ & H3 & 11 & 12 & 13 \\
\hline & $\begin{array}{l}\text { Total reads } \\
\text { (in } \\
\text { millions) }\end{array}$ & 46.92 & 43.37 & 43.99 & 44.84 & 51.05 & 43.75 & 42.82 & 45 & 48.66 & 46.45 & 52.09 & 40.12 \\
\hline & $\begin{array}{l}\text { Mapping } \\
\text { percentage } \\
\text { (to viral } \\
\text { sequence } \\
\text { database) }\end{array}$ & 3.55 & 4.15 & 4.14 & 4.16 & 2.98 & 3.57 & 3.5 & 2.86 & 3.43 & 5.39 & 4.06 & 4.19 \\
\hline \multirow{6}{*}{$\begin{array}{l}\# \\
\text { mapped } \\
\text { reads }\end{array}$} & GYSVd & 75540 & 35948 & 106413 & 117358 & 75834 & 56672 & 7579 & 10356 & 7909 & 14577 & 16708 & 6753 \\
\hline & HSVd & 47507 & 11106 & 39700 & 94212 & 54402 & 38848 & 10159 & 9378 & 8156 & 17867 & 23646 & 9426 \\
\hline & GFLV & & 311949 & & & & & & & & & & \\
\hline & RSPaV & & 27442 & 108582 & 95081 & 134735 & 204412 & 53467 & 71131 & & 110307 & 90850 & 101099 \\
\hline & GRBV & & & & 37642 & 23801 & 54962 & & & & 6118 & 2905 & 4578 \\
\hline & GSyV & & 11934 & & & & & & 5445 & 1952 & & & 992 \\
\hline
\end{tabular}

GYSVd, Grapevine yellow speckle viroid; HSV, hop stunt viroid; GFLV, Grapevine Fan leaf virus; RSPav, Rupestris stem pitting associated virus; GRBV, Grapevine red blotch virus; GSYV, Grapevine Syrah virus. 
Table 2. Structural carbohydrate analysis of GRBD-free (healthy) and GRBD-infected (infected) grapevine cane wood.

\begin{tabular}{|lllll|}
\hline & Merlot & & Syrah \\
\hline Cell wall components & Healthy & Infected & Healthy & Infected \\
\hline Arabinose (Ara) & $1.14 \pm 0.17$ & $1.22 \pm 0.13$ & $1.71 \pm 0.07$ & $1.09 \pm 0.09 *$ \\
\hline Galactose (Gal) & $1.82 \pm 0.09$ & $1.80 \pm 0.08$ & $28.85 \pm 3.58$ \\
\hline Glucose (Glc) & $26.77 \pm 1.36$ & $26.52 \pm 1.81$ & $1.77 \pm 0.00$ \\
\hline Mannose (Man) & $1.50 \pm 0.1$ & $1.55 \pm 0.06$ & $0.55 \pm 0.08$ \\
\hline Rhamnose (Rha) & $0.68 \pm 0.06$ & $0.70 \pm 0.04$ & $13.37 \pm 0.48$ \\
\hline Xylose (Xyl) & $11.93 \pm 1.23$ & $12.04 \pm 1.39$ & $29.88 \pm 1.15$ \\
\hline Lignin (Klason) & $33.54 \pm 0.85$ & $33.45 \pm 1.63$ & 0.79 \\
\hline $\begin{array}{l}\text { The values are shown as average percent } \pm \text { SD for each cell wall component. Significant changes are indicated by asterisk }(*) \text { with p-value } \leq 0.05 \text { as } \\
\text { determined by two-tailed } t \text {-test. }\end{array}$ & & $1.72 \pm 0.09$ \\
\hline
\end{tabular}

\section{Figures}

(a)

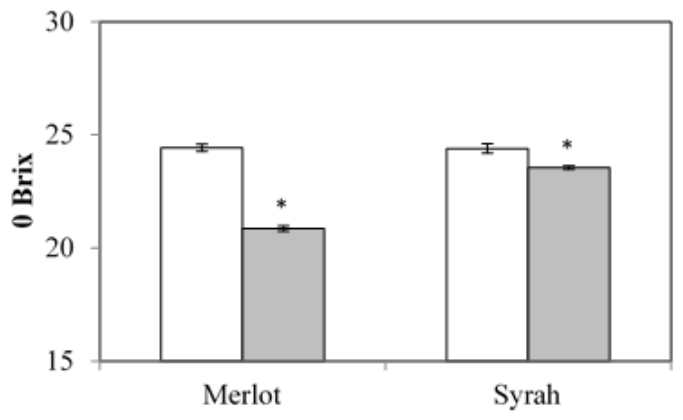

(b)

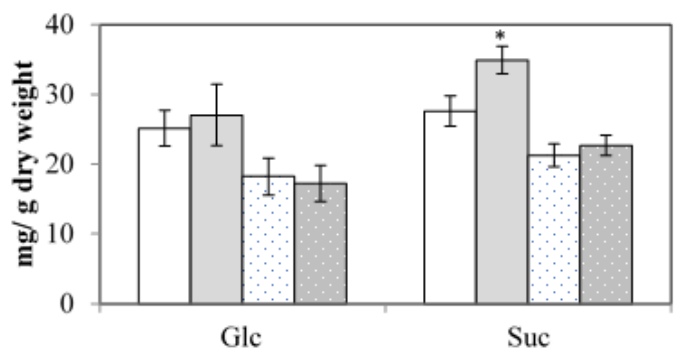

$\square$ Merlot AS $\square$ Merlot S $\square$ Syrah AS $\square$ Syrah S

(c)

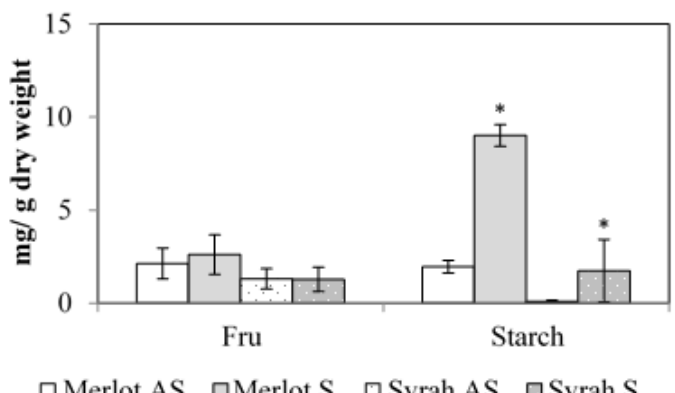

Figure 1

Analysis of berry and leaf soluble carbohydrates in asymptomatic and symptomatic vines. Berry sugars were determined at commercial harvest (a). Leaf soluble sugars and starch were determined in lyophilized mature leaf tissues (B, c). Asterisks indicate significant changes as determined by paired t-test ( $p$ value $\leq 0.05$ ). AS, asymptomatic; $S$, symptomatic samples. 


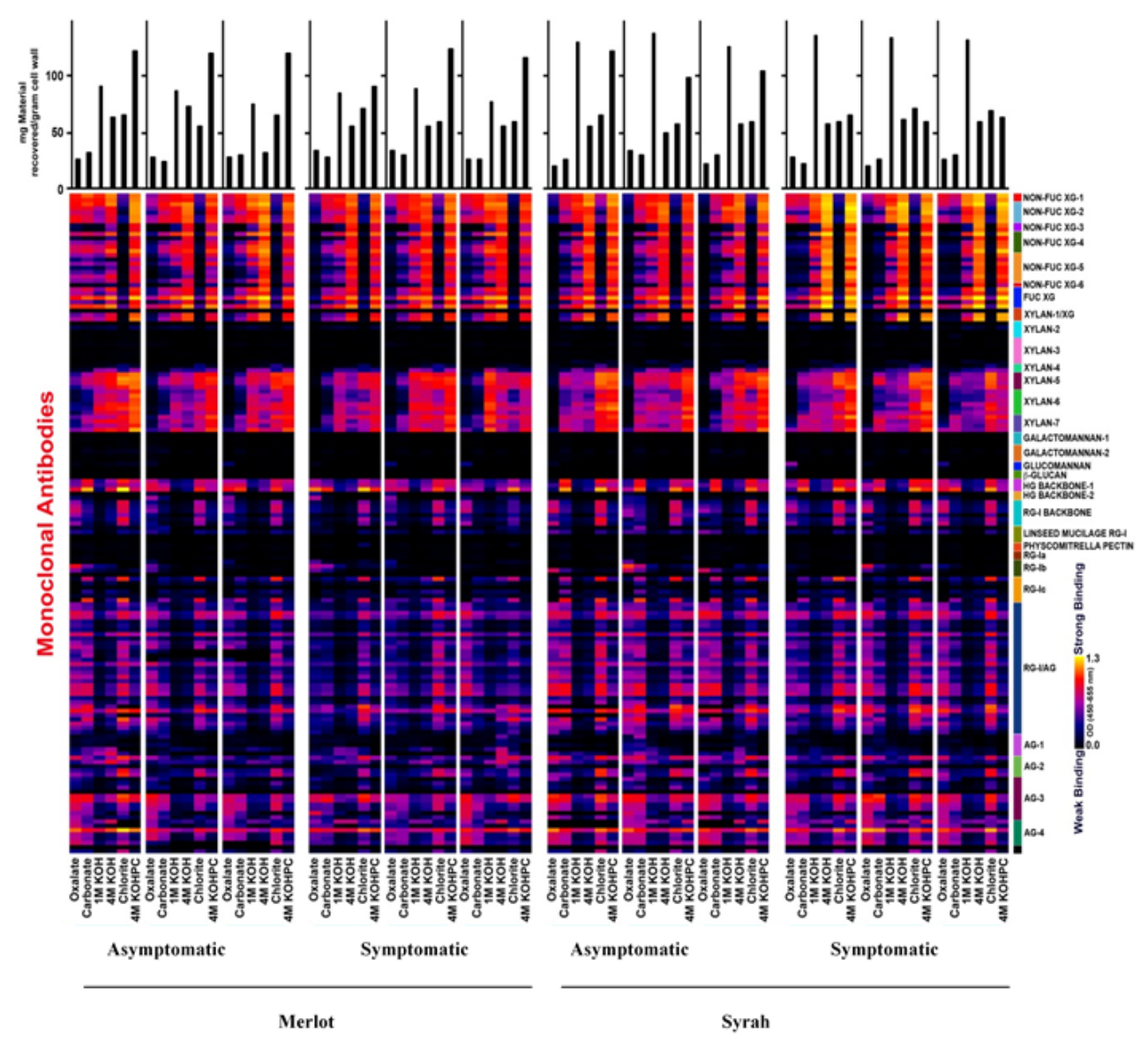

Figure 2

Glycome profiling analyses of winter cane woods of asymptomatic and symptomatic Merlot and Syrah cultivars. Sequential extracts were made from the cane wood cell walls of asymptomatic and symptomatic Merlot and Syrah vine varieties as explained in the method section. The extracts were subsequently screened with a comprehensive suite of cell wall glycan directed mAbs whose glycan specificities are depicted in the right-hand side panel. The binding strengths of the mAbs are depicted as a heatmap color scheme in which brightest yellow, red and dark blue colors depicting strongest, medium and lowest binding respectively. The gravimetric amounts of carbohydrate materials recovered for each extraction is shown as a bar graph on top of the heatmaps. The extraction conditions are depicted in the lower panel. 

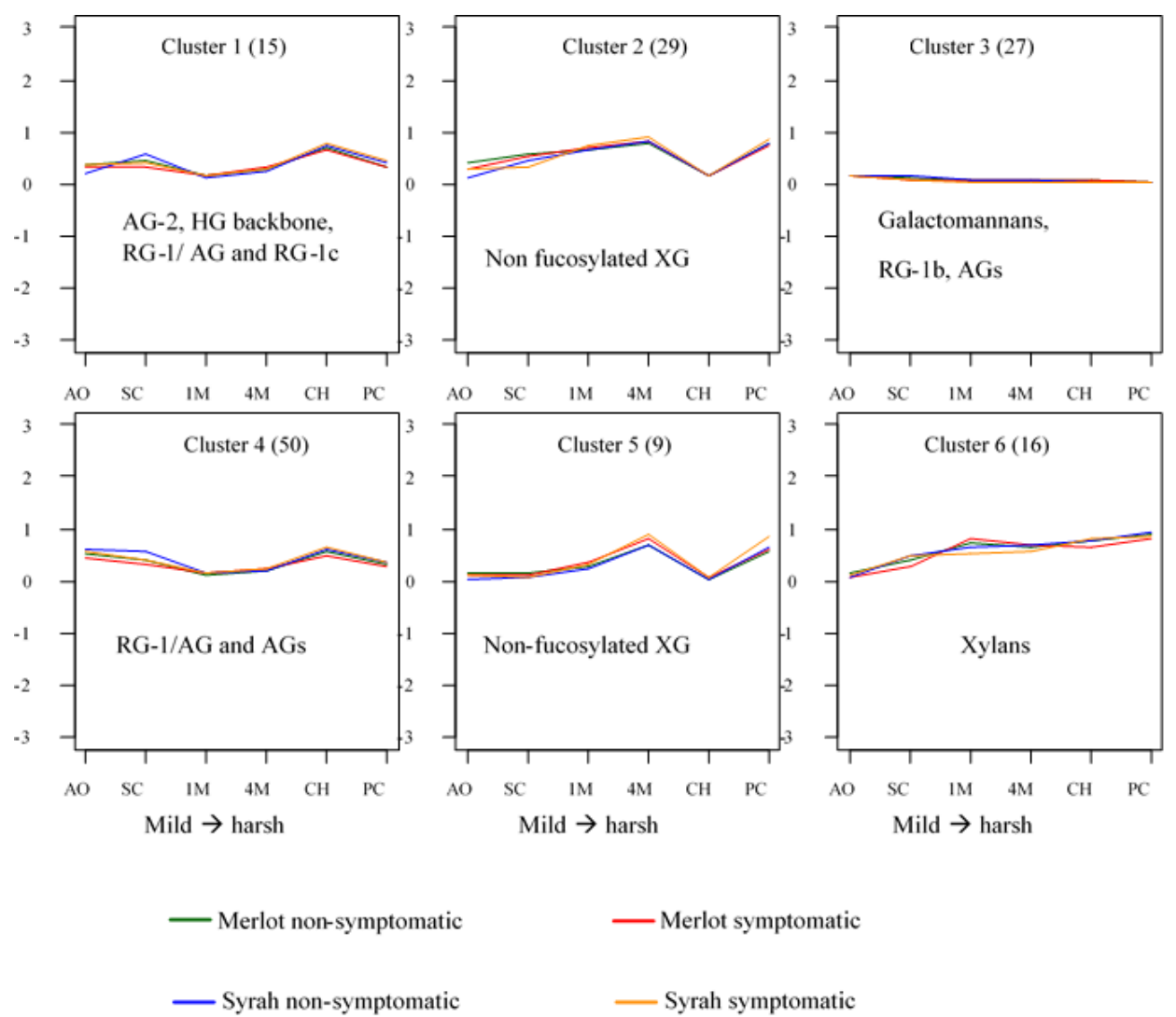

Figure 3

SOM clustering of antibody signal intensities obtained from glycome profiling analyses. The different extraction conditions are shown below each cluster. The number in parenthesis indicate the total number of antibody signals in each cluster.

\section{Supplementary Files}

This is a list of supplementary files associated with this preprint. Click to download.

- FigureS1.docx 